\title{
In-Season Variations in Head Impact Exposure among Youth Football Players
}

\author{
Jillian E. Urban,,2 Mireille E. Kelley,,2 Mark A. Espeland, ${ }^{1,2}$ Elizabeth M. Davenport, \\ Christopher T. Whitlow, ${ }^{2,5,6}$ Alexander K. Powers, Joseph A. Maldjian, and Joel D. Stitzel ${ }^{1,2}$
}

\begin{abstract}
Head impact exposure (HIE) is often summarized by the total exposure measured during the season and does not indicate how the exposure was accumulated, or how it varied during the season. Therefore, the objective of this study was to compare HIE during pre-season, the first and second halves of the regular season, and playoffs in a sample of youth football players ( $n=119$, aged 9-13 years). Athletes were divided into one of four exposure groups based on quartiles computed from the distribution of risk-weighted cumulative exposure $\left(\mathrm{RWE}_{\mathrm{CP}}\right)$. Mean impacts per session and mean 95 th percentile linear and rotational acceleration in practices and games were compared across the four exposure groups and time frames using mixed effects models. Within games, the mean 95th percentile accelerations for the entire sample ranged from $47.2 \mathrm{~g}$ and $2331.3 \mathrm{rad} / \mathrm{sec}^{2}$ during pre-season to $52.1 \mathrm{~g}$ and $2533.4 \mathrm{rad} / \mathrm{sec}^{2}$ during the second half of regular season. Mean impacts per practice increased from pre-season to the second half of regular season and declined into playoffs among all exposure groups; however, the variation between time frames was not greater than two impacts per practice. Time of season had a significant relationship with mean 95th percentile linear and rotational acceleration in games (both, $p=0.01$ ) but not with practice accelerations or impacts per session. The in-practice mean levels of 95th percentile linear and rotational acceleration remained fairly constant across the four time frames, but in games these changed over time depending on exposure group (interactions, $p \leq 0.05$ ). The results of this study improve our understanding of in-season variations in HIE in youth football and may inform important opportunities for future interventions.
\end{abstract}

Keywords: biomechanics; football; head impact exposure; impact magnitude; pediatric

\section{Introduction}

S PORT-RELATED HEAD IMPACTS are of increasing concern as early evidence has demonstrated a relationship between head impact exposure (HIE) experienced in contact sports, such as football, and changes in pre- to post-season imaging and cognitive measures. ${ }^{1-5}$ The nature and extent of this relationship is not well understood; however, with approximately 3.5 million youth athletes playing football, there is a critical need to understand HIE in the sport at this young age. There is a growing body of literature informing our understanding of HIE in youth football. Variations in populationlevel HIE have been observed at the youth level, with the average number of head impacts a youth football player receives in a single season ranging from 107 (7-8 year olds) ${ }^{6}$ to 364 (11-13 years old). ${ }^{7}$

The range in reported exposure per athlete also varies widely within a single team or level of play. Some youth athletes sustain impacts in numbers and magnitudes approaching athletes playing in high school. ${ }^{7}$ For example, in a recent study by Kelley and colleagues, ${ }^{7}$ athletes in the 95 th percentile of total number of impacts among three age- and weight-based levels of play ranged from 568 impacts per season in the youngest and smallest team, to 763 impacts per season in the oldest and heaviest team. For comparison, the average number of head impacts an athlete receives in a single season at the high school level is approximately 500. ${ }^{8,9}$ Some youth football players have been reported to have 95th percentile linear acceleration values exceeding $60 g,{ }^{10,11}$ compared with the 95th percentile value of $57.6 \mathrm{~g}$ reported for a varsity high school football team. ${ }^{8}$ The exposure variation in a single team is not well understood but may be due to several factors, including player position, playing style, coaching techniques, playing experience/ knowledge of tackling and blocking techniques, and volume and intensity of the athlete's training regimen.

Previous studies have demonstrated that HIE measured during a single season is influenced by team-based activities such as the type

\footnotetext{
${ }^{1}$ Department of Biomedical Engineering, ${ }^{3}$ Department of Biostatistical Sciences, ${ }^{5}$ Department of Radiology (Neuroradiology), ${ }^{6} \mathrm{Clinical}$ and Translational Sciences Institute, ${ }^{7}$ Department of Neurosurgery, Wake Forest School of Medicine, Winston-Salem, North Carolina.

${ }^{2}$ Virginia Tech-Wake Forest School of Biomedical Engineering and Sciences, Winston-Salem, North Carolina.

${ }^{4}$ University of Texas Southwestern, Department of Radiology, Dallas, Texas.
} 
of drills conducted as a team. ${ }^{10,12}$ Additionally, mechanics of tackling may play a role in HIE. For example, it has been documented that "struck" players on average experience higher magnitude impacts than "striking" players ${ }^{13,14}$ and contact resulting from greater closing distance results in higher magnitude head impacts. ${ }^{10,15,16}$ However, it is unknown how these factors relate to time of season or how they play a role in cumulative impact exposure of an athlete.

Regardless of the level of play, the football season typically includes a pre-season training period, followed by a series of regular season practices and games that often lead to post-season or playoff practices and games. Prior studies have evaluated in-season variations in football injuries but have primarily focused on collegiate football populations. Several studies evaluating the incidence rate of injury between in-season time frames have reported an increase in overall injury risk during pre-season when compared with regular and post-season. ${ }^{17-20}$ Houck and associates reported the highest practice-related rate of concussion occurred during preseason training camp for National Collegiate Athletic Association (NCAA) D1 Football Players. ${ }^{21}$ Additionally, Steiner and coworkers reported twice as many practice-related injuries during pre-season compared with in-season. ${ }^{22}$

Periodic temporal variations may occur with HIEs. Cumulative exposure is often measured with a single number that amounts to the total exposure measured over the course of the season. Such a measure does not give an indication of how exposure was accumulated, nor how it varies during the season. There is increasing evidence demonstrating a potential link between HIE and brain imaging and neurocognitive changes after a single season ${ }^{1-4,23}$ as well as cognitive impairment and neuropathological evidence of chronic traumatic encephalopathy (CTE) observed after several years of contact sport. ${ }^{24-26}$ It is critically important to gain a better understanding of how HIE varies over the course of the season and how inseason variations differ among athletes with varied levels of total season exposure. Therefore, the objective of this study is to assess how HIE varies during pre-season, the first and second halves of regular season, and playoffs among low- and high-exposure athletes in a sample of youth football players.

\section{Methods}

Head impact data previously reported by Kelley and colleagues were used in this study approved by the Wake Forest School of Medicine Institutional Review Board (IRB). ${ }^{7}$ Athletes participating in at least 1 of 4 consecutive years (2012-15) of youth tackle football within a single league were evaluated in this study. All athletes provided written consent and parental consent to participate in this study. All players were fitted with youth Riddell Speed football helmets containing Head Impact Telemetry System (HITS) MX Encoders in the space between padding in the helmet. The MX Encoder includes accelerometers, a digital encoder, and instrumentation to transmit signals via a wireless antenna to a base unit. Trained research assistants monitored the HIT System at all practices and games. All measured head impacts exceeding $10 \mathrm{~g}$, a commonly used threshold among the HIE literature, ${ }^{7,10,27}$ were recorded. Information from all accelerometers was collected at $1 \mathrm{kHz}$ for a period of $40 \mathrm{msec} ; 8 \mathrm{msec}$ before the trigger and $32 \mathrm{msec}$ after the trigger. Data were screened to remove impacts that did not occur while the helmet was worn (i.e., dropped helmets) using recorded video data. Data processing algorithms and the data collection methodology used in this study were previously published. ${ }^{7,29}$

Cumulative HIE was quantified in terms of combined magnitude and frequency using the risk-weighted cumulative exposure
$\left(\mathrm{RWE}_{\mathrm{CP}}\right)$ metric. $^{8} \mathrm{RWE}$ encompasses magnitude and frequency in an augmented way versus other biomechanical HIE metrics (e.g., number of impacts, percentiles of acceleration) by non-linearly weighting each impact by the estimated concussion risk. ${ }^{8}$ To compute $\mathrm{RWE}_{\mathrm{CP}}$, the risk of concussion for each impact for each player was calculated using the combined probability risk function previously described by Rowson and Duma. ${ }^{29}$ The logistic regression equation with appropriate coefficients was used to compute probability (i.e., risk) of concussion from peak resultant linear and rotational acceleration for each impact. Risks associated with each head impact for each player were summed to compute the $\mathrm{RWE}_{\mathrm{CP}}$ for the season. Athletes were then divided into one of four exposure groups based on quartiles computed from the distribution of $\mathrm{RWE}_{\mathrm{CP}}$. The exposure groups are termed RQ1 to RQ4 for the first to fourth quartiles, respectively.

HIE was compared between pre-season, regular season, and playoffs. Pre-season was defined as the time from the first day of practice up to and including all scrimmage games. The regular season was divided into first and second halves. The first half of the regular season was defined as the first practice after the final preseason scrimmage up to the mid-point in the regular season. The second half of the regular season was defined as the first practice after the mid-point in the regular season up to the last session of the regular season. Playoffs were defined as the first practice after the final regular season session up to the final playoff game.

Mean impacts per session were computed for each athlete and session type (practice or game) within each time frame (i.e., preseason). The 95th percentile linear and rotational acceleration values were calculated from the distribution of each athlete's linear and rotational acceleration profiles within each time frame as well. Mean impacts per session (i.e., practice or game), 95th percentile linear acceleration, and 95th percentile rotational acceleration were compared across each exposure group and time frame using mixed effects models while evaluating the interaction between exposure group and time frame. Mixed effects models were also used to compare athlete characteristics, including age, weight, height, playing experience, and length of season, between exposure groups. Each model was computed while controlling for intraindividual correlations in players across seasons and level of play. ${ }^{7}$ The distribution of impacts per session within each quartile grouping were right-skewed; log-transformations were used to improve symmetry prior to computing the means.

\section{Statistical analysis}

Statistical analysis was performed using SAS version 9.4 (SAS Institute, Inc., Cary, NC).

\section{Results}

In a single youth football organization, over 4 years, 40,538 impacts were recorded from 119 athletes participating at three levels of play. Of those impacts, 5080 were collected during pre-season, 12,897 during the first half of the regular season, 17,127 during the second half of the regular season, and 5434 during playoffs. Athletes were grouped into one of four exposure groups based on quartiles computed from the distribution of $\mathrm{RWE}_{\mathrm{CP}}$. For this sample, the 25 th,

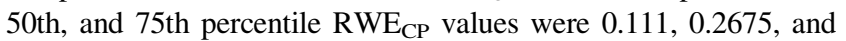
0.5487 , respectively. A summary of the athlete characteristics within each exposure group is provided in Table 1. The distribution of athletes among the exposure groups within each level of play (Level A: age $=10.8 \pm 0.7$ years, weight $=97.5 \pm 11.8 \mathrm{lb}$; Level B: age $=11.9$ \pm 0.5 years, weight $=106.1 \pm 13.8 \mathrm{lb}$; Level C: age $=13.0 \pm 0.5$ years, weight $=126.5 \pm 18.6 \mathrm{lb}$ ) is provided in Figure 1 .

The sample median (and 95th percentile) linear acceleration during the four time frames (pre-season, first half of regular season, 
Table 1. Characteristics of the Youth Football Players within Each Exposure Group

\begin{tabular}{lcccccc}
\hline $\begin{array}{l}\text { Exposure } \\
\text { group }\end{array}$ & $\mathrm{N}$ & Age & Weight & Height & $\begin{array}{c}\text { Playing } \\
\text { experience }\end{array}$ & $\begin{array}{c}\text { Length of season } \\
\text { (days) }\end{array}$ \\
\hline RQ1 & 30 & $11.55(11.22-11.89)$ & $101.65(95.55-107.74)$ & $59.32(57.51-61.14)$ & $2.09(0.73-3.45)$ & $72.13(67.03-77.23)$ \\
RQ2 & 30 & $11.56(11.19-11.93)$ & $108.02(101.00-115.05)$ & $62.17(60.41-63.92)$ & $3.14(1.86-4.42)$ & $79.90(75.94-83.86)$ \\
RQ3 & 30 & $11.88(11.53-12.23)$ & $106.59(100.06-113.13)$ & $60.56(59.22-61.92)$ & $4.04(3.11-4.97)$ & $80.47(75.61-85.33)$ \\
RQ4 & 29 & $12.32(11.95-12.69)$ & $115.48(106.65-124.32)$ & $62.25(60.43-64.07)$ & $4.94(3.72-6.17)$ & $85.79(83.26-88.33)$ \\
\hline P-value* & & 0.04 & 0.13 & 0.20 & 0.12 & 0.009 \\
\hline Overall & 119 & $11.83(11.65-12.01)$ & $107.62(104.14-111.10)$ & $61.16(60.33-61.99)$ & $3.76(3.17-4.34)$ & $79.52(77.30-81.74)$ \\
\hline
\end{tabular}

* $P$-value based on analysis of variance (ANOVA).

second half of regular season, and playoffs) were $20.8 \mathrm{~g}(53.6 \mathrm{~g})$, $20.4 g(52.01 g), 20.9 g(51.6 \mathrm{~g})$, and $21.3 g(54.9 g)$, respectively. The sample median (and 95th percentile) peak rotational acceleration during the four time frames were $960.6 \mathrm{rad} / \mathrm{sec}^{2}\left(2430.2 \mathrm{rad} / \mathrm{sec}^{2}\right)$, $966.4 \mathrm{rad} / \mathrm{sec}^{2}\left(2394.4 \mathrm{rad} / \mathrm{sec}^{2}\right), 976.7 \mathrm{rad} / \mathrm{sec}^{2}\left(2421.2 \mathrm{rad} / \mathrm{sec}^{2}\right)$, and $1003.7 \mathrm{rad} / \mathrm{sec}^{2}\left(2528.3 \mathrm{rad} / \mathrm{sec}^{2}\right)$, respectively.

\section{5th percentile acceleration}

The mean 95th percentile linear and rotational accelerations measured during practices and games within each time frame and exposure group are shown in Figure 2. In both practices and games, the mean 95th percentile linear and rotational acceleration increased with ascending exposure group (i.e., from RQ1 to RQ4; all $p<0.0001$ ). Overall, time of season did not have an effect on the mean 95th percentile linear and rotational accelerations in practices (linear: $p=0.90$ and rotational: $p=0.31$ ), but did have a significant effect in games (linear: $p=0.01$ and rotational: $p=0.01$ ). During practices, increases in mean 95th percentile values among the exposure groups were similar across the time frames of the season (linear: $p=0.66$ and rotational: $p=0.30$; Fig. 2A,C), demonstrating no interaction effect between exposure group and time of season in practices. During games, however, the mean 95th percentile accelerations among the exposure groups tended to vary over the season (linear: $p=0.05$ and rotational: $p=0.04$; Fig. $2 \mathrm{~B}, \mathrm{D}$ ), indicating an interaction effect between exposure group and time of season in games.

Looking specifically at trends within each exposure group, the lowest-exposure athletes (RQ1) experienced a 3.6\% lower mean 95th percentile linear acceleration from pre-season to playoff

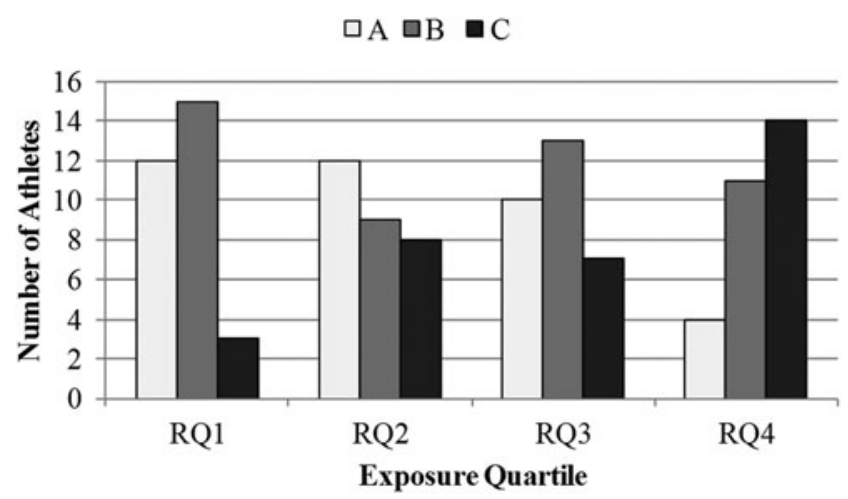

FIG. 1. Distribution of athletes participating at each level of play among the four exposure groups. practices ( $43.7 g$ to $42.1 g$, respectively). RQ2, the second-lowestexposure group, experienced a 5.9\% increase in mean 95th percentile linear acceleration during practices as the season progressed from pre-season to playoffs, from $47.1 \mathrm{~g}$ during pre-season to $49.9 g$ during playoffs (Fig. 2A). For games, a $23.5 \%$ and $33.8 \%$ increase in 95th percentile linear acceleration was measured from pre-season through regular season for the lowest-exposure groups (RQ1: $34.0 \mathrm{~g}$ to $42.0 \mathrm{~g}$ and RQ2: $38.5 \mathrm{~g}$ to $52.7 \mathrm{~g}$ ), followed by a decrease to $33.0 \mathrm{~g}$ and $48.3 g$, respectively, during playoffs (Fig. 2B). Similar trends were observed for mean 95th percentile rotational acceleration, with the exception of an increased mean 95th percentile rotational acceleration for RQ2 during playoffs (Fig. 2C,D).

Players in the higher-exposure quartiles (RQ3 and RQ4) had higher accelerations during the pre-season, with lower 95th percentile accelerations during the latter half of the season (Fig. 2B,D). A $13.2 \%$ and $3.2 \%$ decline in mean 95 th percentile linear acceleration (RQ3: $59.2 \mathrm{~g}$ to $51.4 \mathrm{~g}$ and RQ4: $59.4 \mathrm{~g}$ to $57.5 \mathrm{~g}$ ) was observed from pre-season practices through the second half of regular season practices. However, RQ4 players experienced slightly higher mean 95th percentile linear acceleration ( $3 g)$ during playoff practices compared with regular season (Fig. 2A). For games, the highest mean 95th percentile linear acceleration for RQ3 and RQ4 was observed during the first half of the regular season, followed by a decline into playoffs (Fig. 2B). A similar trend was observed for mean 95th percentile rotational acceleration for RQ4 for games (Fig. 2D). However, the mean 95th percentile rotational acceleration remained relatively constant for RQ3 after pre-season.

\section{Impacts per session}

For the entire sample, the mean (95\% confidence interval [CI]) number of impacts per practice per player during the four time frames (pre-season, first half of regular season, second half of regular season, and playoffs; Fig. 3) were 7.85 (6.82-9.03), 8.93 (8.08-9.78), 10.07 (9.21-11.13), and 8.41 (7.32-9.78), respectively. The mean $(95 \% \mathrm{CI})$ impacts per game per player among the time frames were 7.92 (6.55-9.49), 8.58 (7.24-10.07), 8.76 (7.46$10.18)$, and 9.78 (7.85-12.18), respectively. Time of season did not have an effect on mean impacts per practice, nor mean impacts per game ( $p=0.53$ and $p=0.94$, respectively; Fig. 3 ). Among quartile groups, the number of impacts per practice and game were similar across time frames (practice: $p=0.70$, and game: $p=0.37$ ), indicating no interaction effect between exposure group and time of season for impacts per session. However, a trending increase in the number of impacts per game was observed from pre-season through playoffs for the highest exposure athletes (RQ4). 
Practice

A

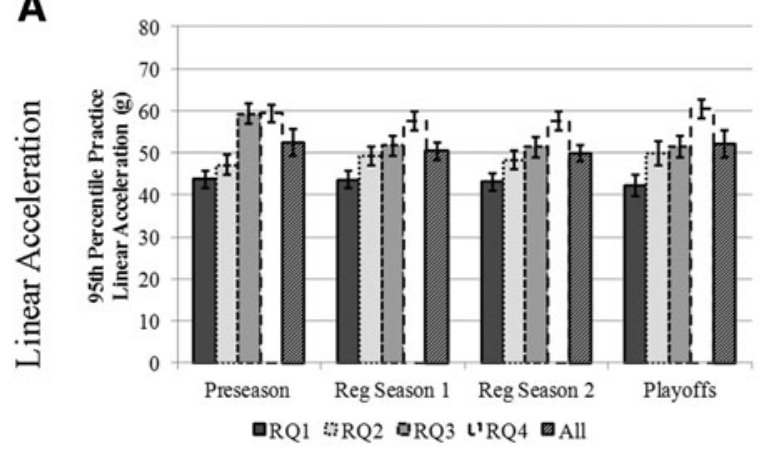

C

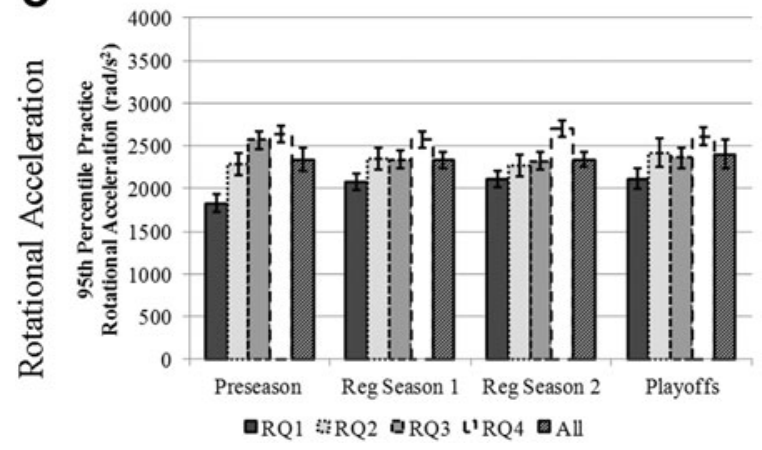

Game

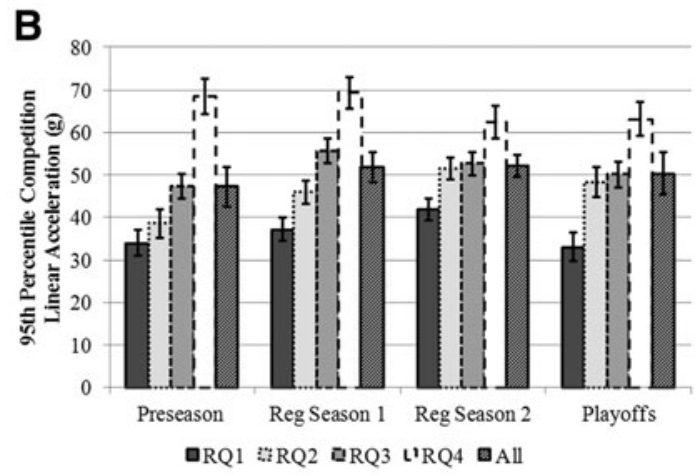

D

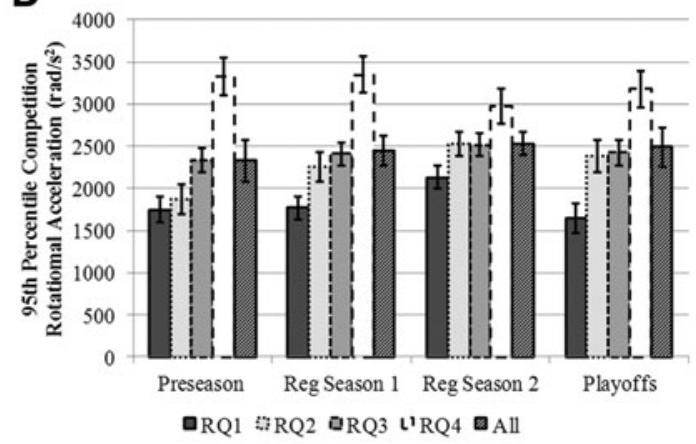

FIG. 2. Mean 95th percentile linear (A,B) and rotational (C,D) acceleration measured during practices $(\mathbf{A}, \mathbf{C})$ and games $(\mathbf{B}, \mathbf{D})$ within the four time frames by quartile. Vertical bars represent the standard error. Time of season had a significant effect on linear $(p=0.01)$ and rotational $(p=0.01)$ acceleration in games. Time of season and exposure group had a significant interaction effect on linear $(p=0.05)$ and rotational $(p=0.04)$ acceleration in games.

\section{Discussion}

The objective of this study was to compare HIE measured during pre-season, the first and second halves of regular season, and playoffs among high- and low-exposure youth football players. The highest 95th percentile values $\left(54.9 g\right.$ and $\left.2528.3 \mathrm{rad} / \mathrm{sec}^{2}\right)$ among the sample were observed during playoffs. Mean impacts per practice were relatively constant throughout the season; however, different trends were observed within each exposure group and session type.

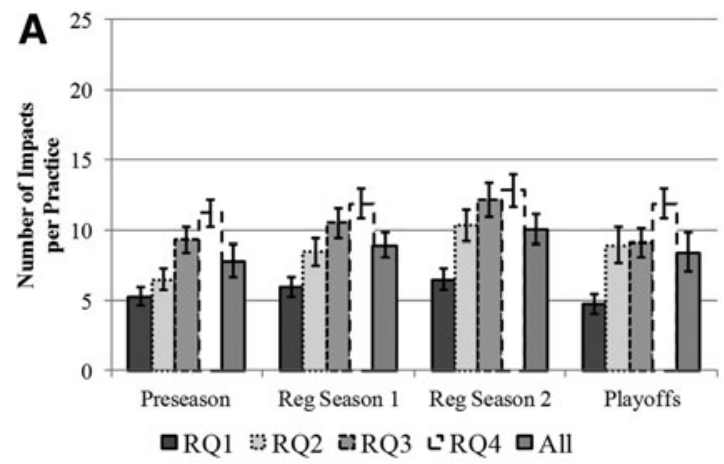

Age and length of season were the only two variables that were significantly different among exposure groups. Mean age, tackle football experience, and season length was greater with each increasing exposure group; however, mean height and weight were not. Higher-exposure athletes often participated on teams that played in more weeks of playoff games, allowing more opportunities for HIE. In fact, there was a 2-week mean difference in season length between the highest- and lowest-exposure athletes. Season length is often ignored when evaluating HIE but is potentially

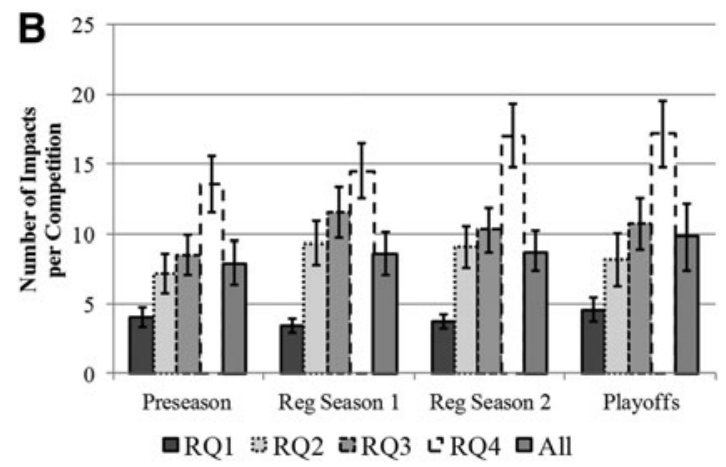

FIG. 3. Number of impacts per practice (A) and number of impacts per game (B) measured during pre-season, regular season, and playoffs for the four exposure quartiles. Vertical bars represent the standard error. No significant main effects or interaction effects were observed. 
important when considering the differences in HIE among different teams or levels of play.

Time of season did not have a significant effect on mean 95th percentile linear and rotational acceleration for practices, but did have an effect for games. Similarly, evaluating interaction between time of season and exposure group, 95th percentile values were similar across time frames of the season within exposure groups for practices but varied significantly for games. Within each exposure group, in practices, the 95th percentile linear and rotational acceleration did not tend to vary much throughout the season, with less than $1 g$ and $200 \mathrm{rad} / \mathrm{sec}^{2}$ difference between many time frames. The mean 95th percentile linear acceleration measured in games among lower exposure athletes (RQ1 and RQ2) increased from preseason through the second half of regular season, but decreased into playoffs. Similar trends were observed among rotational acceleration for RQ1-RQ3. The mean 95th percentile linear acceleration measured in games among higher-exposure athletes (RQ3 and RQ4) increased from pre-season to the first half of regular season, decreased from the first half of regular season to the second half, and decreased again from the second half of regular season to playoffs for RQ3 but remained relatively constant for RQ4 $(<1 g$ difference).

In-season increases in mean 95th percentile linear and rotational acceleration may be related to gains in competency and motivation $^{30-32}$ through the football season, resulting in more involvement in games and subsequent exposure to higher-magnitude hits. ${ }^{7}$ Additionally, pressure is often put on athletes to perform at a higher intensity during games. ${ }^{33}$ Skill development and progression of contact are potentially important factors when evaluating differences in HIE among youth athletes and further research into the relationship with HIE is needed. In-season variations in head impact magnitudes may also be due to several factors, including teambased training regimens, ${ }^{10,27}$ individual on-field behaviors, ${ }^{34}$ and game impact characteristics. ${ }^{15}$ Identifying athletes early in the season who may be at risk for higher exposure or who may be exhibiting risky on-field behavior would provide an opportunity for individual or team-level interventions aimed at reducing exposure.

Time of season did not have a significant effect on the mean impacts per session (practices/games) and no significant interactions were observed between time of season and exposure group. Mean impacts per practice increased from pre-season to the second half of the regular season and declined into playoffs among all exposure groups. However, the variation in impacts per practice between time frames was not greater than 2 impacts per practice, except for RQ3 with 3.1 impacts per practice less during playoffs versus the second half of the regular season.

Teams of athletes participating in this study had approximately two contact practices and one semi-contact practice for $2 \mathrm{~h}$ each per week with varied practice drills determined by the coach. The length of practice during pre-season was generally 30 to $60 \mathrm{~min}$ longer than practices conducted during regular season or playoffs. This variation in total time seemed to have little effect on in-season variations in impacts per practice. The highest-exposure group (RQ4) received approximately 2 times the number of impacts per practice compared with the lowest-exposure group (RQ1) during the season. This finding supports that HIE in practice drills is not equal among athletes and there may be extrinsic factors leading some athletes to engage in more contact during practice drills, such as aggressivity or intensity of play. Schmidt and colleagues did not find level of aggressivity to be related to the number of impacts per practice in youth hockey ${ }^{34}$; however, measures such as this need investigation in youth football to further understand factors associated with HIE variability at the youth level of play.

Impacts per game varied, although not significantly, among time frames and exposure groups. Differences in impacts per game between adjacent time frames were minimal, ranging from 0.17 to 3.1 impacts per game. Fewer impacts per game were measured during pre-season for RQ2, RQ3, and RQ4 compared with the first half of the regular season. Games during this time frame are pre-season scrimmages, which are often shorter and less structured than inseason games. Athletes also may play less aggressively to lower injury risk prior to the regular season. The highest-exposure athletes (RQ4) were the only group with an increasing number of impacts per game as the season progressed. The highest-exposure group (RQ4) received 3 to 4 times the mean number of impacts per game compared with the lowest-exposure group (RQ1) during each time frame. In youth football, athletes often play multiple positions on both offense and defense. High-exposure athletes may be exposed to more playing time and/or may be exposed to positions that are associated with more game HIE. ${ }^{35-38}$

The results of this study provide important insights regarding the in-season variations in HIE in youth football; however, there are limitations that should be considered. First, although data were collected over several years from multiple levels of play, this is a small snapshot of the larger U.S. youth football population. The athletes participated in teams under the guidelines of American Youth Football (AYF) and no specific safe tackling training (i.e., Heads Up Football, Hawk Tackling) was employed. The in-season frequencies and magnitudes may be lower in leagues that have adopted safe tackling programs such as Heads Up Football compared with those presented in the present study. ${ }^{39}$ Rule changes, such as limiting time spent on contact drills in practice, may result in reduced in-season impact frequencies; however, further research is needed to understand how limiting time spent on contact affects impact magnitudes. ${ }^{40}$ The HIT System used in this study has some measurement error for linear $(0.9 \%)$ and rotational $(6.1 \%)$ acceleration, with research suggesting that the HIT System may overestimate peak acceleration values. ${ }^{41,42}$ Acceleration measurement errors are within the range of acceptable error for other measurement devices and methods but should be taken into consideration when interpreting the results of this study. Additionally, the HIT System is the most widely used commercial head impact sensor. ${ }^{42}$ The concussion risk curve used to group the athletes into exposure groups is derived from the collegiate population and may not directly translate to concussion risk in the youth population; however, RWE is a metric that non-linearly weighs the magnitude of each head impact and encompasses both the number and magnitude of impacts an athlete received on aggregate. Lastly, in-season variations in weather (e.g., extreme heat, rain, lightning) were not accounted for in this study but may affect practice length and/or intensity, and subsequently the magnitude and frequency of hits.

The results of this study demonstrate variations in head impact frequency and magnitude measured throughout the season within a sample of youth football players. Time of season had a significant effect on mean 95th percentile linear and rotational acceleration in games but not on practice accelerations or impacts/session. Significant interaction effects between exposure group and time of season in games on mean 95th percentile accelerations were observed. The mean number of impacts per practice and game did not vary significantly with time of season but the higher exposure athletes experienced an increasing number of impacts per game as the season progressed. The results of this study improve our 
understanding of in-season variations in HIE in youth football and may inform important opportunities for future interventions.

\section{Acknowledgments}

Research reported in this publication was supported by the National Institute of Neurological Disorders And Stroke of the National Institutes of Health under award numbers R01NS094410 and R01NS082453. The National Center for Advancing Translational Sciences, National Institutes of Health, through Grant KL2TR001421 supported Dr. Jillian Urban. The content is solely the responsibility of the authors and does not necessarily represent the official views of the National Institutes of Health. Special thanks to the Childress Institute for Pediatric Trauma at Wake Forest Baptist Medical Center for providing support for this study. The authors would like to thank the leaders, coaches, parents, athletes, and athletic trainers (Mary Kopacki, LAT, ATC and Erica Cheramie, LAT, ATC) of the youth football organization for their continued support for our efforts. The authors would also like to thank Kamah Woelfel, Amanda Dunn, Matt Bennett, Meghan Thompson, Eliza Szuch, Danielle Rocheleau, Joeline Kane, Katie Fabian, Ana Katsafanas, Megan Anderson, and Leslie Hoyt for their valuable assistance in data collection.

\section{Author Disclosure Statement}

No competing financial interests exist.

\section{References}

1. Davenport, E.M., Apkarian, K., Whitlow, C.T., Urban, J.E., Jensen, J.H., Szuch, E., Espeland, M.A., Jung, Y., Rosenbaum, D.A., Gioia, G.A., Powers, A.K., Stitzel, J.D., and Maldjian, J.A. (2016). Abnormalities in diffusional kurtosis metrics related to head impact exposure in a season of high school varsity football. J. Neurotrauma 33, 2133-2146.

2. Davenport, E.M., Whitlow, C.T., Urban, J.E., Espeland, M.A., Jung, Y., Rosenbaum, D.A., Gioia, G.A.G.G.A., Powers, A.K., Stitzel, J.D. and Maldjian, J.A. (2014). Abnormal white matter integrity related to head impact exposure in a season of high school varsity football. J. Neurotrauma 1624, 1617-1624.

3. Bazarian, J.J., Zhu, T., Blyth, B., Borrino, A., and Zhong, J. (2012) Subject-specific changes in brain white matter on diffusion tensor imaging after sports-related concussion. Magn. Reson. Imaging 30, 171180

4. Chun, I.Y., Mao, X., Breedlove, E.L., Leverenz, L.J., Nauman, E.A., and Talavage, T.M. (2015). DTI detection of longitudinal WM abnormalities due to accumulated head impacts. Dev. Neuropsychol. 40, 92-97.

5. Bahrami, N., Sharma, D., Rosenthal, S., Davenport, E.M., Urban, J.E., Wagner, B., Jung, Y., Vaughan, C.G., Gioia, G.A., Stitzel, J.D., Whitlow, C.T., and Maldjian, J.A. (2016). Subconcussive head impact exposure and white matter tract changes over a single season of youth football. Radiology 281, 919-926.

6. Daniel, R.W., Rowson, S., and Duma, S.M. (2012). Head impact exposure in youth football. Ann. Biomed. Eng. 40, 976-981.

7. Kelley, M.E., Urban, J.E., Miller, L.E., Jones, D.A., Espeland, M.A., Davenport, E.M., Whitlow, C.T., Maldjian, J.A., and Stitzel, J.D. (2017). Head impact exposure in youth football: comparing age and weight based levels of play. J. Neurotrauma 34, 1939-1947.

8. Urban, J.E., Davenport, E.M., Golman, A.J., Maldjian, J.A., Whitlow, C.T., Powers, A.K., and Stitzel, J.D. (2013). Head impact exposure in youth football: high school ages 14 to 18 years and cumulative impact analysis. Ann. Biomed. Eng. 41, 2474-2487.

9. Broglio, S.P., Sosnoff, J.J., Shin, S., He, X., Alcaraz, C., and Zimmerman, J. (2009). Head impacts during high school football: a biomechanical assessment. J. Athl. Train. 44, 342-349.

10. Kelley, M.E., Kane, J.M., Espeland, M.A., Miller, L.E., Powers, A.K., Stitzel, J.D., and Urban, J.E. (2017). Head impact exposure measured in a single youth football team during practice drills. J. Neurosurg. Pediatr. 20, 489-497.
11. Daniel, R.W., Rowson, S., and Duma, S.M. (2014). Head impact exposure in youth football: middle school ages 12 to 14 years. J. Biomech. Eng. 136, 094501.

12. Cobb, B.R., Urban, J.E., Davenport, E.M., Rowson, S., Duma, S.M., Maldjian, J.A., Whitlow, C.T., Powers, A.K., and Stitzel, J.D. (2013). Head impact exposure in youth football: elementary school ages 9-12 years and the effect of practice structure. Ann. Biomed. Eng. 41, 2463-2473.

13. Viano, D.C., Casson, I.R., and Pellman, E.J. (2007). Concussion in professional football: biomechanics of the struck player-part 14 . Neurosurgery 61, 313-328.

14. Viano, D.C., and Pellman, E.J. (2005). Concussion in professional football: biomechanics of the striking player-part 8 . Neurosurgery 56, 266-280; discussion 266-280.

15. Schmidt, J.D., Guskiewicz, K.M., Mihalik, J.P., Blackburn, J.T., Siegmund, G.P., and Marshall, S.W. (2016). Head impact magnitude in American high school football. pediatrics 138, e20154231e20154231.

16. Ocwieja, K.E., Mihalik, J.P., Marshall, S.W., Schmidt, J.D., Trulock, S.C., and Guskiewicz, K.M. (2012). The effect of play type and collision closing distance on head impact biomechanics. Ann. Biomed. Eng. 40, 90-96.

17. Gunnoe, A.J., Horodyski, M., Tennant, L.K., and Murphey, M. (2001). The effect of life events on incidence of injury in high school football players. J. Athl. Train. 36, 150-155.

18. Gabbett, T.J., and Domrow, N. (2007). Relationships between training load, injury, and fitness in sub-elite collision sport athletes. J. Sports Sci. 25, 1507-1519.

19. Kay, M.C., Register-Mihalik, J.K., Gray, A.D., Djoko, A., Dompier, T.P., and Kerr, Z.Y. (2017). The Epidemiology of Severe Injuries Sustained by National Collegiate Athletic Association Student-Athletes, 2009-2010 Through 2014-2015. J. Athl. Train. 52, 117-128.

20. Agel, J., and Schisel, J. (2013). Practice Injury Rates in Collegiate Sports. Clin. J. Sport Med. 23, 33-38.

21. Houck, Z., Asken, B., Bauer, R., Pothast, J., Michaudet, C., and Clugston, J. (2016). Epidemiology of sport-related concussion in an NCAA Division I Football bowl subdivision sample. Am. J. Sports Med. 44, 2269-2275.

22. Steiner, M.E., Berkstresser, B.D., Richardson, L., Elia, G., and Wang, F. (2016). Full-contact practice and injuries in college football. Sports Health 8, 217-223.

23. Nauman, E.A., Breedlove, K.M., Breedlove, E.L., Talavage, T.M., Robinson, M.E., and Leverenz, L.J. (2015). Post-season neurophysiological deficits assessed by ImPACT and fMRI in athletes competing in american football. Dev. Neuropsychol. 40, 85-91.

24. Stamm, J.M., Bourlas, A.P., Baugh, C.M., Fritts, N.G., Daneshvar, D.H., Martin, B.M., McClean, M.D., Tripodis, Y., and Stern, R.A. (2015). Age of first exposure to football and later-life cognitive impairment in former NFL players. Neurology 84, 1114-1120.

25. Stern, R.A., Riley, D.O., Daneshvar, D.H., Nowinski, C.J., Cantu, R.C., and McKee, A.C. (2011). Long-term consequences of repetitive brain trauma: chronic traumatic encephalopathy. PM R. (10 Suppl. 2), S460-S467.

26. Alosco, M.L., Tripodis, Y., Jarnagin, J., Baugh, C.M., Martin, B., Chaisson, C.E., Estochen, N., Song, L., Cantu, R.C., Jeromin, A., and Stern, R.A. (2017). Repetitive head impact exposure and later-life plasma total tau in former National Football League players. Alzheimers Dement. (Amst.) 7, 33-40.

27. Campolettano, E.T., Rowson, S., and Duma, S.M. (2016). Drillspecific head impact exposure in youth football practice. J. Neurosurg. Pediatr. 18, 536-541.

28. Crisco, J.J., Chu, J.J., and Greenwald, R.M. (2004). An algorithm for estimating acceleration magnitude and impact location using multiple nonorthogonal single-axis accelerometers. J. Biomech. Eng. 126, 849854.

29. Rowson, S., and Duma, S.M. (2013). Brain injury prediction: assessing the combined probability of concussion using linear and rotational head acceleration. Ann. Biomed. Eng. 41, 873-882.

30. Dawes, N.P., Vest, A., and Simpkins, S. (2014). Youth participation in organized and informal sports activities across childhood and adolescence: exploring the relationships of motivational beliefs, developmental stage and gender. J. Youth Adolesc. 43, 1374-1388.

31. Wagnsson, S., Lindwall, M., and Gustafsson, H. (2014). Participation in organized sport and self-esteem across adolescence: the mediating role of perceived sport competence. J. Sport Exerc. Psychol. 36, 584-594. 
32. Theeboom, M., Knop, P. De, and Weiss, M.R. (1995). Motivational Climate, Psychological Responses, and Motor Skill Development in Children's Sport: A Field-Based Intervention Study. J. Sport Exer. Psych. 17, 294-311.

33. Oudejans, R.R.D., Kuijpers, W., Kooijman, C.C., and Bakker, F.C. (2011). Thoughts and attention of athletes under pressure: skill-focus or performance worries? Anxiety Stress Coping 24, 59-73.

34. Schmidt, J.D., Pierce, A.F., Guskiewicz, K.M., Register-Mihalik, J.K., Pamukoff, D.N., and Mihalik, J.P. (2016). Safe-play knowledge, aggression, and head-impact biomechanics in adolescent ice hockey players. J. Athl. Train. 51, 366-372.

35. Mihalik, J.P., Bell, D.R., Marshall, S.W., and Guskiewicz, K.M. (2007). Measurement of head impacts in collegiate football players: an investigation of positional and event-type differences. Neurosurgery 61, 1229-1235.

36. Crisco, J.J., Fiore, R., Beckwith, J.G., Chu, J.J., Brolinson, P.G., Duma, S., McAllister, T.W., Duhaime, A.-C., and Greenwald, R.M. (2010). Frequency and location of head impact exposures in individual collegiate football players. J. Athl. Train. 45, 549-559.

37. Broglio, S.P., Martini, D., Kasper, L., Eckner, J.T., and Kutcher, J.S (2013). Estimation of head impact exposure in high school football: implications for regulating contact practices. Am. J. Sports Med. 41, 2877-2884.

38. Broglio, S.P., Eckner, J.T., Martini, D., Sosnoff, J.J., Kutcher, J.S., and Randolph, C. (2011). Cumulative head impact burden in high school football. J. Neurotrauma 28, 2069-2078.
39. Kerr, Z.Y., Yeargin, S.W., Valovich McLeod, T.C., Mensch, J., Hayden, R., and Dompier, T.P. (2015). Comprehensive coach education reduces head impact exposure in American youth football. Orthop. J. Sport. Med. 3, 232596711561054

40. Cobb, B.R., Urban, J.E., Davenport, E.M., Rowson, S., Duma, S.M., Maldjian, J.A., Whitlow, C.T., Powers, A.K., and Stitzel, J.D. (2013). Head impact exposure in youth football: Elementary school ages 9-12 years and the effect of practice structure. Ann. Biomed. Eng. 41, 2463-2673.

41. Allison, M.A., Kang, Y.S., Bolte, J.H., Maltese, M.R., Arbogast, K.B., Bolte IV, J.H., Maltese, M.R., and Arbogast, K.B. (2014). Validation of a helmet-based system to measure head impact biomechanics in ice hockey. Med. Sci. Sports Exerc. 46, 115-123.

42. Beckwith, J.G., Greenwald, R.M., and Chu, J.J. (2012). Measuring head kinematics in football: correlation between the head impact telemetry system and Hybrid III headform. Ann. Biomed. Eng. 40, 237-248.

Address correspondence to: Jillian E. Urban, PhD, MPH

Virginia Tech-Wake Forest School of Biomedical Engineering and Sciences 575 N. Patterson Avenue, Suite 120 Winston-Salem, NC 27101

E-mail: jurban@wakehealth.edu 